\title{
Disruption of delayed matching to sample
}

\author{
GERALD D. LACHTER and HARRIET SCHLACKMAN \\ C. W. Post College of Long Island University, Greenvale, New York 11548
}

\begin{abstract}
Two pigeons were exposed to a 3-sec delayed matching-to-sample (DMTS) procedure. Following acquisition, reinforcement for sample responding was presented during the delay interval. After baseline recovery, a blackout procedure was instituted during the delay interval. Both procedures reduced the accuracy of responding on the DMTS task. Accuracy was below that seen in baseline sessions. In addition, reductions in sample-specific behaviors were obtained with both procedures. The data support and extend the notion that sample-specific behaviors mediate accurate DMTS performance.
\end{abstract}

Investigations of short-term memory in nonhuman subjects have typically made use of a delayed matchingto-sample procedure (Blough, 1959). In this procedure, responses to the sample center-key stimulus terminate that stimulus and, after a delay interval, produce comparison stimuli on the two side keys. Correct matching responses are followed by reinforcement, and incorrect matches typically produce a blackout.

A number of variables have been shown to affect accuracy on a delayed matching-to-sample task, including increases in the delay interval (Grant, 1975), other interpolated activities (Roberts \& Grant, 1976), interference factors (Nelson \& Wasserman, 1978), and changes in illumination (Tranberg \& Rilling, 1980).

If delayed matching-to-sample performance depends upon sample-specific behaviors, then factors that decrease these behaviors should reduce the accuracy of performance. Data reported by Zental, Hogan, Howard, and Moore (1978) indicate that this is indeed the case.

The present investigation attempted to evaluate disruptions in delayed matching-to-sample performance produced by reinforcement or blackout during the delay interval.

\section{METHOD}

\section{Subjects}

Two White King hen pigeons were maintained and trained at $80 \%( \pm 15 \mathrm{~g})$ of their free-feeding weights. Both subjects had previously been exposed to a 3 -sec delayed matching-to-sample procedure for approximately 60 sessions.

\footnotetext{
Apparatus

A standard Lehigh Valley Electronics three-key pigeon chamber was used. A force of approximately $.25 \mathrm{~N}$ was required to close each key switch. The keys could be transilluminated by red or green light produced by a $12-\mathrm{V}$ IEE stimulus projector. Overall chamber illumination could be provided by a $28-\mathrm{V}$ houselight located above the center key. Reinforcement consisted of $3 \mathrm{sec}$ access to a lighted hopper of mixed grain. An exhaust fan provided ventilation and, in conjunction with $80 \mathrm{~dB}$ of white noise, served to mask extraneous sounds.

\section{Procedure}

Both subjects were exposed to a $3-\mathrm{sec}$ delayed matching-tosample procedure. A trial began with the illumination of the
}

center key. Following 16 responses (FR 16), the center key was extinguished, and a 3 -sec delay interval followed. During the delay, all keys were dark and the houselight was illuminated. Following the delay, the side keys were illuminated. A correct color match resulted in reinforcement, and an incorrect match produced a $5 \mathrm{sec}$ blackout. The presentation of red and green sample stimuli on the center key and the red and green comparison stimuli on the side keys was randomized from trial to trial. Each session consisted of 48 trials. This baseline procedure was in effect for 45 sessions.

Following baseline, reinforcement for $3 \mathrm{sec}$ was made available during the delay interval. All other contingencies remained the same as in the baseline procedure. This procedure was in effect for 12 sessions.

Baseline was reinstated for an additional 12 sessions, followed by a procedure in which the chamber was totally dark during the delay interval. This blackout procedure was in effect for 12 sessions.

\section{RESULTS AND DISCUSSION}

By the end of the initial baseline period, both subjects were responding to the delayed matching-tosample task at approximately $80 \%$ correct (see Figure 1 ).

Introducing reinforcement following completion of the sample requirement reduced the level of accuracy to approximately $60 \%$. When the baseline procedure was reinstated, both subjects showed a return in accuracy to at or near baseline performance. This recovery occurred more slowly for Subject 2 than for Subject 1. The blackout procedure produced a disruption that was similar to that produced by reinforcement. Although accuracy was slightly higher for Subject 1 , the general pattern was similar to that seen earlier.

Since both interventions reduced responding during the delay interval, the reductions in accuracy that occurred provide support for the notion that the development of sample-specific responding is necessary in delayed matching to sample. As has been previously noted, changing conditions during the delay interval disrupts accurate matching performance. The present data support and extend this finding by demonstrating that reinforcement, as well as blackout, can disrupt matching performance by interfering with the development of sample-specific responding. 


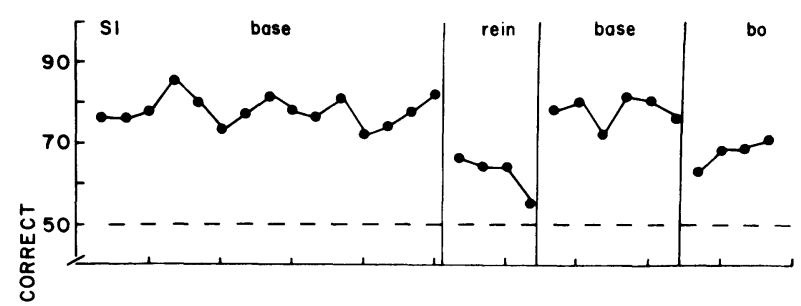

\section{REFERENCES}

Blough, D. S. Delayed matching in the pigeon. Journal of the Experimental Analysis of Behavior, 1959, 2, 151-160.

Grant, D. S. Proactive interference in pigeon short-term memory. Journal of Experimental Psychology: Animal Behavior Processes, 1975, 104, 207-220.

Nelson, K. R., \& Wasserman, E. A. Temporal factors influencing the pigeons successive matching-to-sample performance: Sample duration, intertrial interval, and retention interval. Journal of the Experimental Analysis of Behavior, 1978, 30, 153-162.

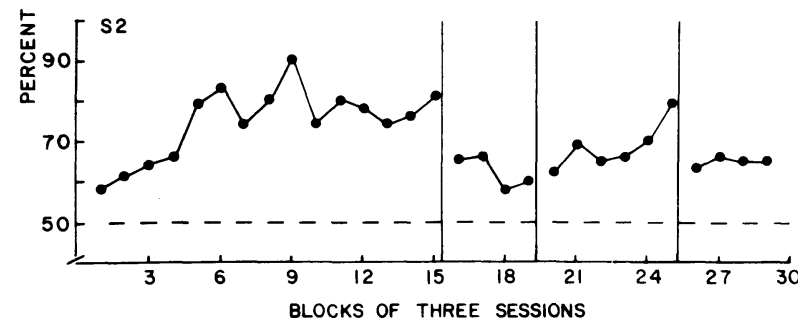

Figure 1. Percent correct responses for both subjects across all phases of the experiment. "Base" indicates baseline conditions, "rein" indicates reinforcement during the delay interval, and "bo" indicates the blackout condition. Each point is the mean of three sessions. The dashed horizontal line indicates chance performance.
Roberts, W. A., \& Grant, D. S. Studies of short-term memory in the pigeon using the delayed matching to sample procedure. In D. L. Medin, W. A. Roberts, \& R. T. Davis (Eds.), Processes of animal memory. Hillsdale, N.J: Erlbaum, 1976.

Tranberg, D. K., \& Rilling, M. Delay-interval illumination changes interfere with pigeon short-term memory. Journal of the Experimental Analysis of Behavior, 1980, 33, 39-49.

Zental, T. R., Hogan, D. E., Howard, M. M., \& Moore, B. S. Delayed matching in the pigeon: Effect on performance of sample-specific observing responses and differential delay behavior. Learning and Motivation, 1978, 9, 202-218.

(Received for publication August 24, 1981.) 